\title{
The Effects of Residual Stress on Elastic-Plastic Fracture: Two Diffraction Studies
}

\author{
Harry Coules ${ }^{1, a^{*}}$, Graeme Horne ${ }^{1, b}$ and Matthew Peel ${ }^{1, c}$ \\ ${ }^{1}$ University of Bristol, Queens Building, University Walk, Bristol BS8 1TR, United Kingdom \\ aharry.coules@bristol.ac.uk, bgraeme.horne@bristol.ac.uk, matthew.peel@bristol.ac.uk \\ * Corresponding author
}

\begin{abstract}
Keywords: Residual Stress, Fracture Mechanics, Neutron Diffraction, Synchrotron XRay Diffraction, Finite Element Analysis
\end{abstract}

\begin{abstract}
Brittle fracture in structural materials is strongly influenced by the presence of residual stresses. During more ductile fractures the influence of residual stress is reduced by plastic deformation prior to the initiation of fracture. In structural integrity assessments, it is therefore important to account for the interaction between applied loads and residual stresses. This interaction was studied in two experiments. In the first, residual stresses in aluminium alloy 7075-T6 three-point bend specimens were measured prior to loading using neutron diffraction. In the second, the stress field in compact tension specimens of ferritic pressure vessel steel was mapped using energydispersive synchrotron X-ray diffraction as the specimens were loaded. In both cases, finite element modelling of the elastic-plastic fracture was performed using residual stresses either reconstructed from, or validated using, experimental results. This method of analysis allowed us to compare the effect of residual stress on two different fracture mechanisms. The aluminum specimens fractured in brittle manner, and analysis of experimental load-displacement results showed that residual stresses were superimposed almost linearly with externally-applied stresses at the point of fracture initiation. In the steel specimens, fracture initiated by ductile tearing and it was shown using finite element analysis that residual stress had only a very small effect on the crack-driving force at higher levels of applied load. In fact, at the point of tearing initiation prior strain-hardening caused by the indentation process used to introduce residual stresses had a greater effect on the crack-driving force than the residual stress state itself.
\end{abstract}

\section{Introduction}

Residual stresses can strongly affect the initiation of fracture in brittle materials [1]. However, in more ductile fractures the effect is diminished by partial relaxation of the residual stress, which is enabled by plasticity prior to fracture initiation. As a consequence, some structural integrity assessment procedures such as the R6 procedure [2] and the British Standard BS7910:2013 [3] include methods to account for this effect. This is achieved using approximate methods. For example, in the Failure Assessment Diagram (FAD) approach used in R6, a plasticity correction factor V is introduced to represent the reduction in the effect of "secondary" stresses. Secondary stresses are defined as those stresses that can influence fracture initiation but do not contribute to plastic collapse when this is the dominant failure mechanism. Typically, residual and thermal stresses are classed as secondary. By contrast "primary" loads are those which affect both failure mechanisms and include, for example, pressurisation and gravity loads. Although it is relatively simple to apply, the plasticity correction method can give overly-conservative results for some geometries. In certain situations, disproportionately severe plastic deformation can occur close to a defect as a result of high residual stresses remote from it - a situation referred to as elastic follow-up. In cases where there is significant elastic follow-up, the $\mathrm{V}$ factor approach has the potential to give a non-conservative assessment result unless the elastic follow-up effect is considered [4]. 
In the past, the interaction between primary and secondary stresses during fracture has been widely studied using finite element analysis, often for the purpose of developing improved techniques for structural integrity assessment. However, there has been little experimental work on this topic due to the difficulty involved in measuring the complex stress fields which occur close to a crack tip. We performed two experiments to observe these stress fields and, using this data in conjunction with finite element analysis, investigated the effect of residual stress on the mechanism of elastic-plastic fracture [5], [6].

\section{Method}

Brittle fracture. Single Edge Notched Bend (SEN(B)) specimens of 7075-T6 aluminium alloy with dimensions $120 \times 30 \times 15 \mathrm{~mm}$ were prepared as shown on Fig 1. Half of the $16 \mathrm{SEN}(\mathrm{B})$ specimens were compressed in the out-of-plane direction using a pair of circular indenters, before the "crack" (actually an Electrical Discharge Machined notch) was cut into them. The other half were notched in the as-received condition. The residual elastic strain field on the mid-thickness plane of the specimen in the region of the notch (see Fig 1) was measured using neutron diffraction. The measurements were performed using the SALSA diffractometer at the Institut Laue-Langevin (Grenoble, France). Measurements were taken at $2.5 \mathrm{~mm}$ intervals over most of the measurement plane and at $1 \mathrm{~mm}$ intervals in a small region surrounding the crack tip. Finally, both the indented and non-indented sets of specimens were loaded to failure in three-point bending and their apparent plane-strain fracture toughness was calculated.

Elastic-plastic finite element analysis was performed to estimate the elastic-plastic strain energy release rate at the point of fracture for both sets of specimens. This analysis used a residual stress field for the indented specimens that was reconstructed from the measured neutron diffraction data using an iterative technique [7]. Loading of the residually-stressed specimen was then simulated and the energy release rate was determined by calculating the J-integral as a function of throughthickness position on the crack front. To account for the effect of residual stress, the modified Jintegral formulation due to Lei was used [8], [9].

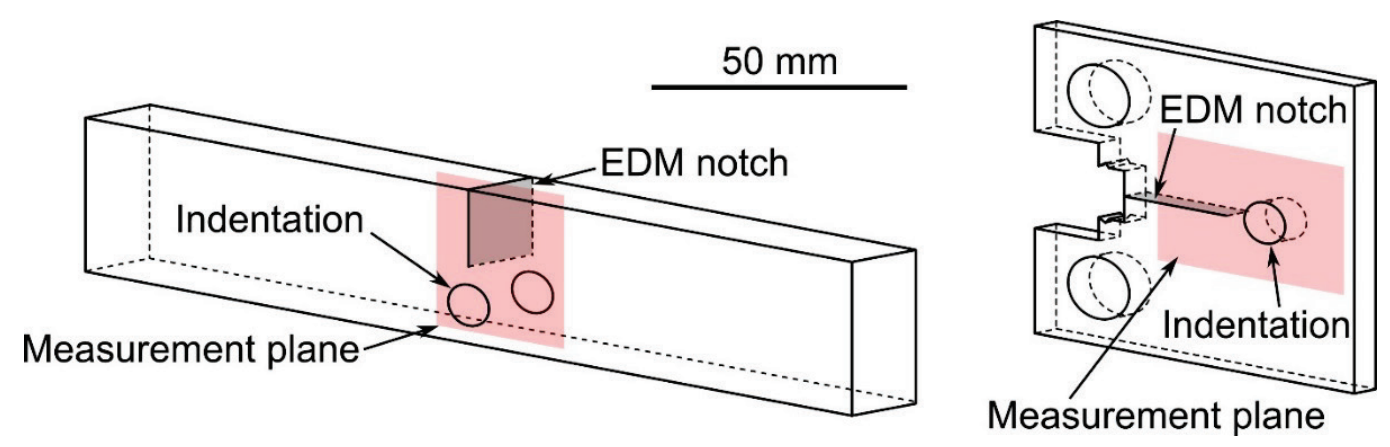

Figure 1: Indented Single Edge Notched $(S E N(B))$ and Compact Tension $(C(T))$ fracture specimens used in the experiments.

Ductile tearing. This experiment used modified Compact Tension $(\mathrm{C}(\mathrm{T})$ ) specimens of a ferritic pressure vessel steel (Fig 1). As in the previous experiment, a residual stress field was introduced in some of the specimens by local compression ahead of the notch tip. However, the steel specimens exhibited a much more ductile fracture process and were loaded until the initiation of ductile tearing. Loading of the specimens was carried out on the I12 beamline at Diamond Light Source (Oxfordshire, UK). Energy-Dispersive X-ray Diffraction (EDXD) was used to measure the stress field surrounding the crack at incremental loading steps at a spatial resolution of $1 \mathrm{~mm}$ over most of the specimen, and $0.25 \mathrm{~mm}$ in a region surrounding the crack tip. X-ray radiography was used to detect the initiation of ductile tearing at the notch tip (Fig 2c). 
a.

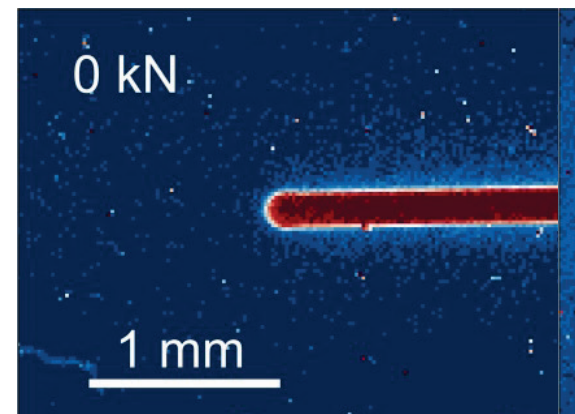

b.

c.

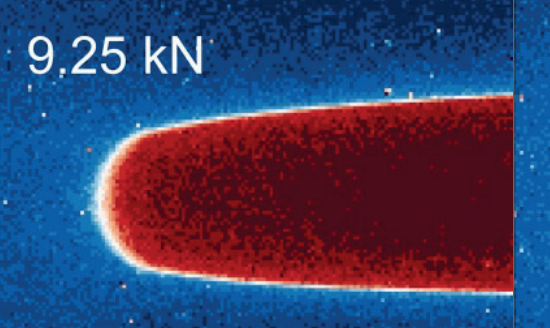

\section{$9.80 \mathrm{kN}$}

Figure 2: X-ray images of the notch tip of a $C(T)$ specimen at three levels of applied load, showing the initiation of ductile tearing in $c$.).

As in the brittle fracture experiment, finite element analysis was performed to predict the specimens' elastic-plastic strain energy release rate. However, the initial residual stress field assumed to exist when modelling the steel $\mathrm{C}(\mathrm{T})$ specimens was derived from elastic-plastic modelling of the indentation process, validated using the EDXD measurements taken at incremental loading steps.

\section{Results and discussion}

In both experiments, we measured the residual stress field that resulted from out-of-plane compression followed by introduction of a crack. Results for each type of specimen under zero external load are shown in Fig 3. Significant opening-mode crack loading occurs under the action of residual stress alone in both the $\mathrm{SEN}(\mathrm{B})$ and the $\mathrm{C}(\mathrm{T})$ specimens.

a.

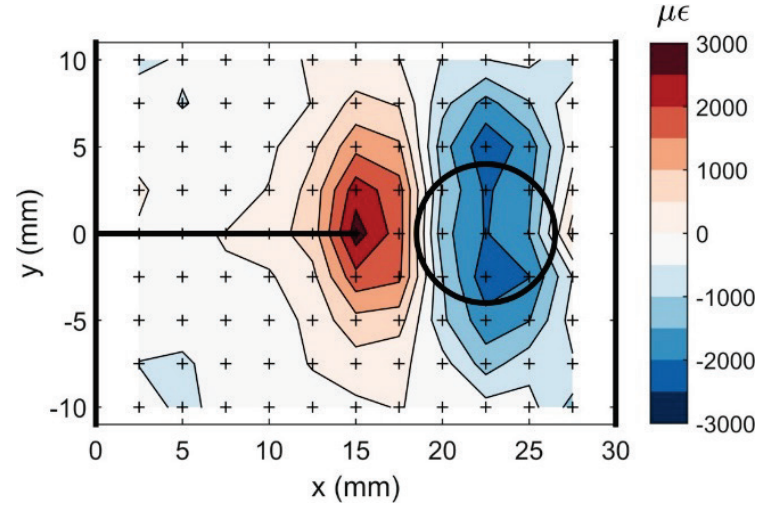

b.

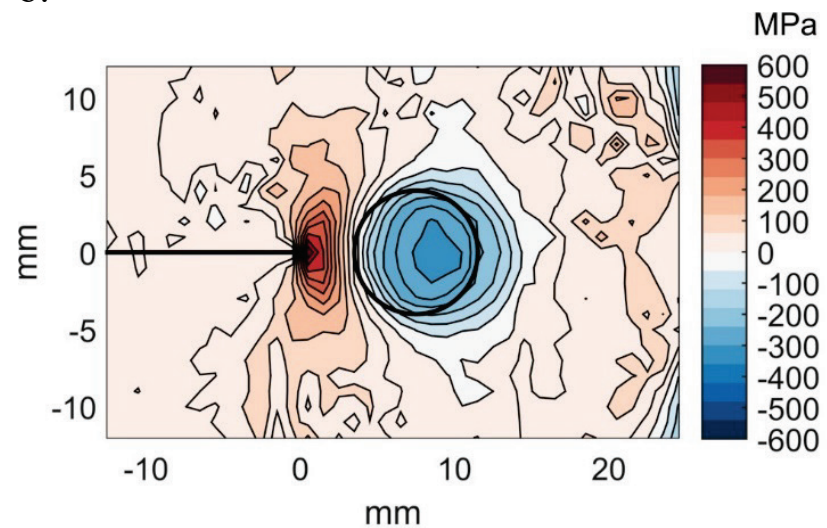

Figure 3: Measured residual elastic strain and residual stress fields around crack tips in two fracture specimens. In each case the crack-transverse component of strain/stress is shown. a.) Residual elastic strain in an aluminium alloy 7075-T6 three-point bend specimen, measured using neutron diffraction. Crosses indicate measurement gauge volume centres. b.) Residual stress in a modified compact tension specimen of pressure vessel steel, measured using EDXD.

The contribution of residual stress to the stress intensity factor for the SEN(B) specimens was calculated via the weight function method using neutron diffraction data from an indented but unnotched specimen. This calculation predicted a contribution of $11.3 \mathrm{MPa} \sqrt{\mathrm{m}}$ from residual stress. Under three-point bend loading, the SEN(B) specimens all failed in an almost completely brittle manner. The load at failure was used to calculate the contribution of externally-applied loading to the apparent Mode I stress intensity factor. The indented (i.e. residually-stressed) specimens fractured at a consistently lower load than the unindented ones. As shown in Fig 4, the difference in apparent fracture toughness was $13.2 \mathrm{MPa} V \mathrm{~m}$. Therefore the reduction in apparent Mode I plane strain 
fracture toughness was similar to the contribution of residual stress to the crack-tip stress intensity, as would be expected for a brittle fracture.

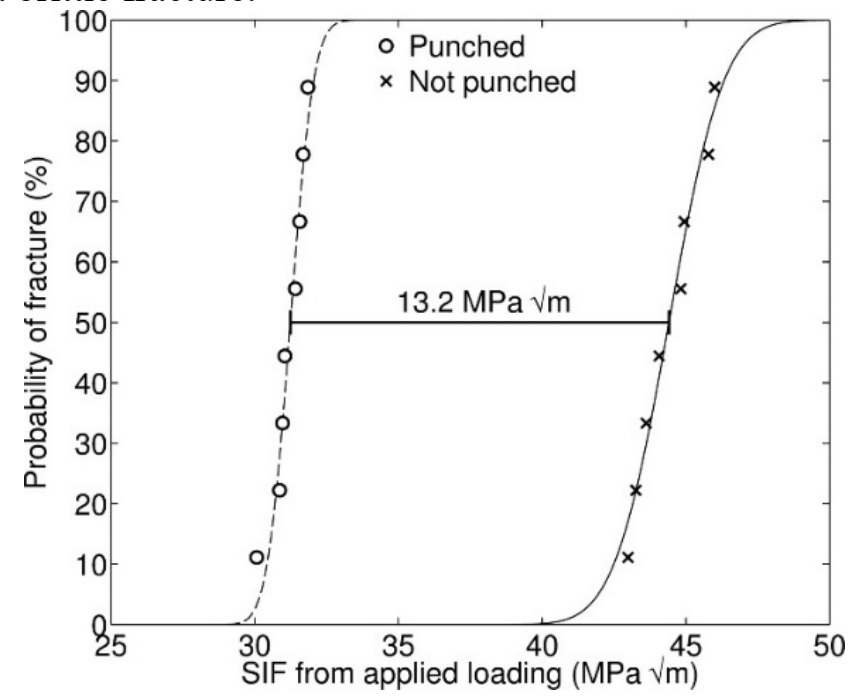

Figure 4: Curves indicating the cumulative probability of failure for indented and unindented $S E N(B)$ specimens, based on the results of 16 fracture tests.

The stress field within the $\mathrm{C}(\mathrm{T})$ specimens was measured not only under zero external load (as shown in Figure $3 b$ ), but also at incremental loading steps up to the initiation of tearing. Figure 5 compares measured distributions of stress surrounding the crack in an indented specimen with those calculated using FEA. There is good agreement between the two methods and it was concluded that the FEA results were sufficiently accurate for reliable calculation of the elastic-plastic strain energy release rate.
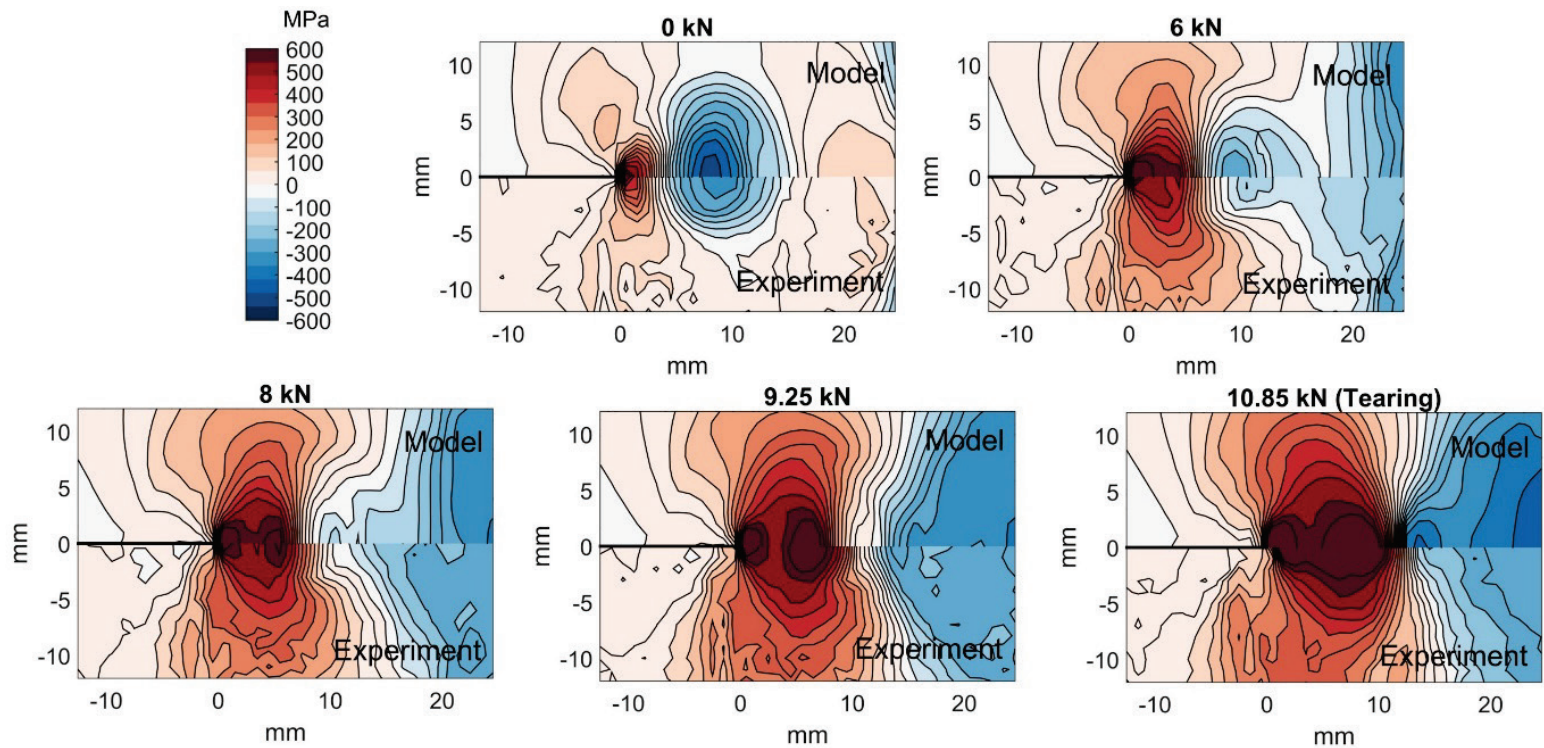

Figure 5: Stress distribution (crack-transverse $\sigma_{y y}$ component shown) on the mid-thickness plane of an indented $C(T)$ specimen at different levels of applied loading. Results are shown for elasticplastic FEA (model) and data measured using EDXD (experiment).

Elastic-plastic equivalent stress intensity factor results calculated from finite element analysis of the SEN(B) and C(T) loading tests are shown in Fig 6. The crack-driving force is initially zero for the specimens containing no residual stress (solid blue lines), while there is a finite crack-driving force for the indented specimens (solid red lines). The SEN(B) specimens (Fig 6a) exhibited almost 
perfectly brittle fracture; their $\mathrm{K}_{\mathrm{J}}$ values deviate only a small amount from the result for a theoretical perfectly-elastic specimen (dashed lines). For the indented SEN(B) specimens, the model included an initial residual stress field reconstructed from neutron diffraction measurements. By comparing the through-thickness distribution of $\mathrm{K}_{\mathrm{J}}$ at fracture to that for an unindented specimen, it was concluded that the reconstruction technique was a viable method for incorporating measured residual stress data into the elastic-plastic analysis of fracture.

a.

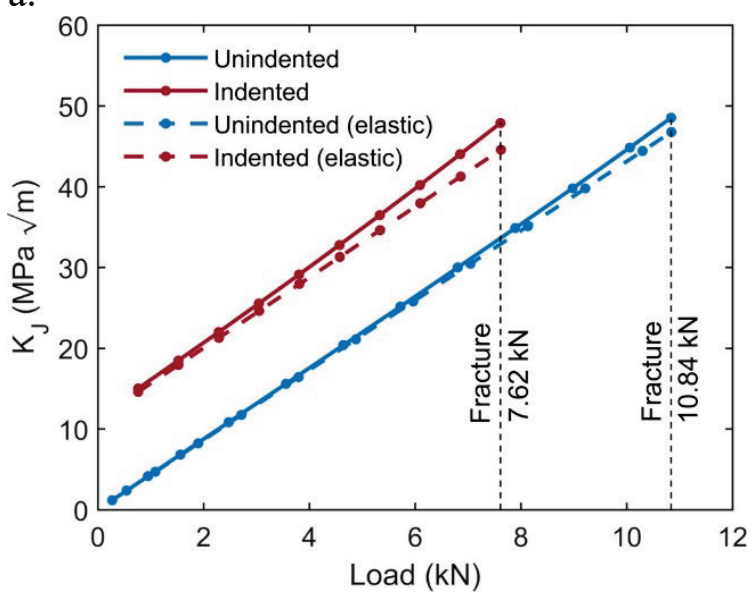

b.

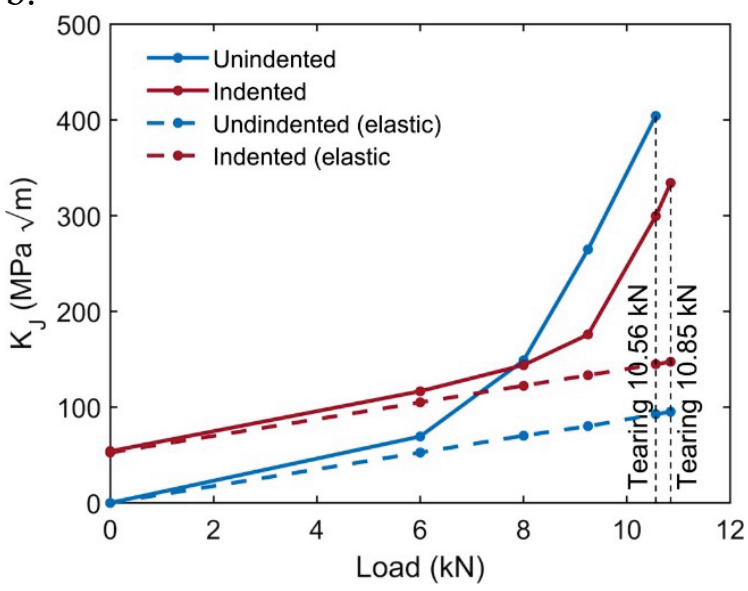

Figure 6: Elastic-plastic equivalent stress intensity factor at the mid-thickness of four specimens (two SEN(B) specimens and two C(T) specimens) as a function of applied load. Mode I SIF for a theoretical perfectly-elastic specimen is also shown in each case. a.) $\operatorname{SEN}(B)$ specimens, $b$.) $C(T)$ specimens. Note different vertical scales.

The C(T) specimens (Fig 6b) show a much more ductile fracture than the SEN(B) specimens, and so deviate strongly away from the predictions of linear-elastic theory. Surprisingly, $\mathrm{K}_{\mathrm{J}}$ for the unindented specimen rises above that for the indented specimen at higher levels of applied load. Using FEA, it was shown that this is due to strain-hardening of the material during indentation. This strain-hardening causes a spatial variation in initial hardness in the indented specimen which, like residual stress, affects the distribution of plastic deformation that occurs in the specimen as it is loaded to failure. Most structural integrity assessment procedures, including R6, contain relatively detailed treatment of residual stresses but put less emphasis on the effect of spatial variations in initial material hardness. These results suggest that hardness variations resulting from the processes which introduce residual stress may have a more significant effect on ductile fracture than is often considered. In future experiments, we plan to use the techniques developed here to study fracture occurring under elastic follow-up conditions, and the effect of primary/secondary stress interaction on elastic-plastic crack propagation.

\section{Conclusions}

1. The contribution of two well-characterised residual stress fields to the initiation of brittle fracture and ductile tearing has been analysed.

2. A method for incorporating measured residual stress data into elastic-plastic cracked-body finite element analysis of fracture via iterative reconstruction of the stress field was shown to be viable.

3. Variations in the strain-hardening state of material often occur in conjunction with residual stress. For ductile fractures, such variations can have a significant effect on the elastic-plastic strain energy release rate. 


\section{Acknowledgements}

Access to the SALSA diffractometer was provided by the Institut Laue-Langevin (proposal no. 1-02-148) and access to the I12 beamline was provided by Diamond Light Source Ltd. (proposal no. EE11463). We are grateful to Mr Paulo Orrock, Dr Kiranmayi Abburi Venkata, Dr Thilo Pirling, Mr Sam Oliver, Dr Derreck Van Gelderen, Dr Thomas Connolley and the late Prof. David Smith who all assisted with the work described in this article.

\section{References}

[1] P. J. Withers, "Residual stress and its role in failure," Reports on Progress in Physics, vol. 70, no. 12, pp. 2211-2264, 2007. http://dx.doi.org/10.1088/0034-4885/70/12/R04

[2] R6: Assessment of the Integrity of Structures Containing Defects, Revision 4, Amendment 11. EDF Energy, Gloucester, 2015.

[3] BS 7910:2013 - Guide to methods for assessing the acceptability of flaws in metallic structures. BSi, 2013.

[4] R. A. Ainsworth, "Consideration of elastic follow-up in the treatment of combined primary and secondary stresses in fracture assessments," Engineering Fracture Mechanics, vol. 96, pp. 558569, 2012. http://dx.doi.org/10.1016/j.engfracmech.2012.09.009

[5] H. E. Coules, G. C. M. Horne, M. J. Peel, S. J. Oliver, D. G. A. V. Gelderen, and T. Connolley, "Direct observation of elastic and plastic strain fields during ductile tearing of a ferritic steel," in Proceedings of the ASME 2016 Pressure Vessels \& Piping Conference, 2016, no. 63345.

[6] H. E. Coules, D. J. Smith, P. J. Orrock, K. A. Venkata, and T. Pirling, "A combined experimental and modelling approach to elastic-plastic crack driving force calculation in the presence of residual stresses," Experimental Mechanics (in press), 2016. http://dx.doi.org/10.1007/s11340-016-0171-0

[7] H. E. Coules, D. J. Smith, K. A. Venkata, and C. E. Truman, "A method for reconstruction of residual stress fields from measurements made in an incompatible region," International Journal of Solids and Structures, vol. 51, no. 10, pp. 1980-1990, 2014. http://dx.doi.org/10.1016/j.ijsolstr.2014.02.008

[8] Y. Lei, "J Calculation for a crack in a welding residual stress field following a FE welding simulation," in Transactions of SMiRT 23 Manchester, United Kingdom - August 10-14, 2015, 2015, p. 213.

[9] Y. Lei, "J-integral evaluation for cases involving non-proportional stressing," Engineering Fracture Mechanics, vol. 72, no. 4, pp. 577-596, 2005. http://dx.doi.org/10.1016/j.engfracmech.2004.04.003 